\title{
ENTREVISTA COM AHARON APPELFELD
}

\section{INTERVIEW WITH AHARON APPELFELD}

Réquiem pelo povo judeu que foi exterminado - assim o professor e crítico israelense denominou a obra e o feito literário de Aharon Appelfeld. Em outro momento, frisou que Appelfeld é o mais judeu dos escritores israelenses.

No início da carreira, Appelfeld dedicou-se à descrição de personagens alquebrados e oprimidos de sobreviventes do Holocausto, tentando juntar os fragmentos de vidas nos campos de deslocados e em Israel. Então, ele voltou o olhar aos anos anteriores à guerra e abordou, com sensibilidade e sutileza, a experiência de judeus assimilados na Europa Central, que se recusaram a interiorizar a catástrofe galopante que se aproximava e que os conduziria, involuntariamente, à destruição. Em um terceiro conjunto das obras, Appelfeld retornou ao final do século XIX e início do século XX e examinou o processo de distanciamento da sociedade judaica de suas raízes tradicionais, com o enfraquecimento da antiga identidade tribal-religiosa. Somente numa etapa relativamente mais tardia é que o famoso autor conseguiu defrontar-se de forma direta com os anos do terror, mais de uma vez expostos a partir da perspectiva de um menino da mesma idade que ele tinha então, o qual tinha passado pelo período da guerra numa expedição de sobrevivência entre os campos de trabalho forçado, vilarejos, campos e florestas da Ucrânia.

A contribuição e a importância de Appelfeld e de sua obra não devem ser resumidas apenas ao título de "literatura da shoá". As qualidades únicas da obra de Appelfeld lhe conferem um lugar de honra na literatura israelense, na qual ele ocupa uma posição de destaque há mais de meio século.

Poucos livros de Appelfeld foram traduzidos ao português. Reconhecendo a importância do muitas vezes premiado escritor israelense e considerando serem entrevistas capazes de aproximar leitores a autores, os Cadernos de Língua e Literatura Hebraica the abrem espaço mais uma vez, trazendo a tradução de uma entrevista publicada pelo periódico Forward, na sua seção em ídiche. A primeira entrevista de Appelfeld foi publicada no número 2, de 1999 
(realizada e traduzida por mim, N.R.), e a segunda, publicada no número 11, de 2013 (realizada e traduzida por Luís Sérgio Krausz e Naamá Silverman-Forner).

Nancy Rozenchan*

* Professora Sênior de Língua e Literatura Hebraica da Faculdade de Filosofia, Letras e Ciências Humanas da Universidade de São Paulo. 


\title{
Aharon Appelfed: um Escritor Ídiche em Hebraico ${ }^{1}$
}

\author{
Benny Mer
}

A Rua Al'Harizi, em Jerusalém, é uma espécie de rua paradisíaca. No meio da grande cidade barulhenta, essa ruazinha silenciosa se oculta. Quase nenhum carro passa por ali. Podem-se ouvir passarinhos e avistar as velhas casas hierosolimitas de Rechávia.

Antigamente, viviam ali as antigas elites: professores, ministros e outros. Os tempos mudaram, e hoje vivem ali também novos ricos. Justamente por isso, continua a existir ali uma espécie de prazer respeitável. A Rua Al'Harizi, com todas as suas árvores, flores, plantas e pássaros, parece quase uma aldeia, e, talvez, não por acaso, é bem ali que vive o escritor Aharon Appelfeld. Sua casa, envolta por árvores e plantas, fez-me lembrar, por um instante, a sua antiga casa na Bucovina, onde ele nasceu em 1932.

A ruazinha silenciosa no meio da ruidosa Jerusalém combina com o escritor também por outros motivos: sua tranquilidade é uma exceção para nós, em Israel; é difícil ouvir suas falas delicadas entre as buzinas, mesmo no meio literário. Além disso, quando vemos o escritor, parece que a sua tranquilidade encobre muitos gritos, exatamente como a ruazinha de Jerusalém. Pois é muito raro encontrar uma infância tão difícil como a dele.

A mãe de Appelfeld foi morta a tiros quando ele tinha apenas oito anos. Depois, ele, junto com o pai, foi levado de casa, em Czernowitz, para Transnístria e, logo em seguida, foi separado do pai. Ele, apenas uma criança, perambulou pelas florestas junto com marginais ucranianos. Nenhum traço dessas experiências sombrias é perceptível em seu rosto, e seus ecos não são audíveis em suas falas. Tudo é traduzido segundo o seu padrão: silencioso, limpo e claro. De qualquer modo, a Rua Al'Harizi é um lugar adequado para escrever mais um livro, um acréscimo para os 45 que publicou.

Em um dos seus livros, Sipur Chaim [História de Vida, Ed. Kéter, 1999], o senhor escreve que, após uma visita à casa dos avós, como criança de oito anos, o senhor entendeu que era "mudo. Jamais conseguirei falar com Deus, pois não sei a língua dele." Qual era, então, a sua língua quando criança?

\footnotetext{
${ }^{1}$ Publicado em Forward, em 21 de junho de 2016, edição de 25 de junho de 2016. Disponível em: $<$ http://yiddish.forward.com/articles/197536/aaron-applefeld-a-yiddish-writer-in-hebrew/> Tradução e notas de Nancy Rozenchan.
} 
Quando eu visitava o meu avô nas montanhas dos Cárpatos, costumava ir com ele à sinagoga. Com eles, com a vovó e com o vovô, eu costumava falar ídiche. Mas com meus pais eu falava alemão. Só alemão. Para mim, como criança, a separação era nítida. Mais ainda: meus pais falavam comigo em um estilo purista de alemão, para que o ídiche, Deus o livre, não estragasse o meu alemão. Do ponto de vista deles, alemão era o mundo moderno, cultura, música, literatura; e ídiche, todas as coisas antiquadas. Eles não ocultavam o seu judaísmo, mas absolutamente não o cultivavam.

Ou seja, eu tinha raízes tanto em alemão como em ídiche. Mas eu as perdi totalmente durante os anos da guerra. Cheguei a Israel em 1946, com 13 anos, sem nenhuma língua. Eu falava ucraniano e russo, mas isso não valia nada. Precisei aprender hebraico. Não tinha alternativas. Naquela época, eu vivia na aldeia de crianças de Rachel Yanait Ben Tsvi. Depois, vivi em diversos kibutzim e, assim, obtive um vocabulário mínimo em hebraico.

Quando entrei para o exército, em 1950, o oficial corrigia os meus erros e, quando dei baixa, dois anos mais tarde, eu ainda continuava confuso: nem para cá, nem para lá; nem ídiche, nem hebraico. Aos poucos, entendi que, se quero me tornar um escritor ídiche, devo aprender ídiche de novo e, assim, ingressei na universidade, no departamento de ídiche.

\section{Isto foi uma resistência ao "sabrismo"?}

Não era uma questão de resistência. Entendi que era um destino diferente e um caráter diferente. O "sabrismo" não tinha a ver comigo. Não estive na Palmach ou no Étsel. Não havia o que fazer.

Tive o privilégio de ter tido como professor o fundador dos estudos ídiches na Universidade Hebraica, o Prof. Dov Sadan [Shtok]. Felizmente, não havia muitos alunos no grupo, e era quase uma aula particular. A maior parte das aulas era quando passeávamos. O ensinamento de Sadan era associativo: ele me apresentou Peretz, Mêndele, Sholem-Aleichem. Mas eu aprendi ídiche não só na universidade. Eu ia sozinho ao bairro de Mea Shearim para

\footnotetext{
${ }^{2}$ A política vigente na época direcionava os imigrantes a assumirem logo a nova identidade do país e a língua e cultura hebraicas, aqui representadas pelo termo sabrismo, baseado no fruto sabra, então abundante no país. $\mathrm{O}$ sabra, espinhoso por fora e doce por dentro, serviu de alcunha para o israelense nativo, pela rudeza exterior e doçura interior.
} 
ouvir ídiche e, simultaneamente, assistir a uma aula de halachá, chassidismo ou ia comprar um livro de tema religioso.

O senhor conta e escreve que seus pais eram judeus assimilados. Talvez o ídiche tenha sido para o senhor uma oposição contra a educação estabelecida por eles. Ou seja, seria um retorno à língua de seu avô?

Meus avós eram realmente praticantes do hassidismo ${ }^{3}$, o hassidismo de Sadgora. Mas eu não vivi com eles mais do que oito anos. Meu interesse pelo ídiche provém não só de motivos biográficos. Além de o ídiche ser uma língua bonita, ele é também uma parte da criação cultural do povo judeu nos últimos mil anos. Se se deseja estar em contato com o mundo judaico, é preciso conhecer o ídiche. É um meio de se ligar às correntes judaicas, como os bundistas ${ }^{4}$ e os comunistas, mas também à era hassídica antes da destruição. De modo geral, o ídiche se tornou, para mim, um símbolo de judaísmo, e entendi que, sem o ídiche, é impossível tornar-se um escritor ídiche.

\section{Isto significa que o ídiche foi um meio de retornar?}

Não de retornar ao judaísmo, mas aprender judaísmo. Naquela época, na década de cinquenta, graças a Dov Sadan, travei conhecimento com seus amigos, os professores Guershon Sholem e Martin Buber. Eles estavam encantados pelos textos ídiches, não lhes importava a origem deles, cabala ou Shabetai Zvi. Ídiche também pertencia aos textos judaicos que lhes agradaram. Certa vez, Buber me disse que um chassid grita na sua oração "Doce Pai" e que tal atributo ele, Buber, jamais tinha ouvido. Em nenhuma cultura, chama-se Deus de "doce".

\section{Naquela época, o senhor começou a escrever em hebraico?}

Naquela época, teve início a minha cristalização como escritor ídiche em língua hebraica. Não me tornei um escritor telavivense, como Natan Alterman e Avraham Shlonsky,

\footnotetext{
${ }^{3}$ Movimento surgido no interior do judaísmo ortodoxo que promove a espiritualidade, através da popularização e internalização do misticismo judaico, como um aspecto fundamental da fé judaica.

${ }^{4}$ Partidários do Bund, União Judaica Trabalhista da Lituânia, Polônia e Rússia.
} 
por exemplo, que criaram, surpreendentemente, uma cultura universal. Em Jerusalém, era diferente. Aqui, judeus assimilados, como Buber e Sholem, quiseram justamente se aproximar do judaísmo. Isso foi do meu agrado e me encantou. Eles até leram meus primeiros contos em hebraico e me estimularam.

\section{O senhor também conviveu com o ambiente ídiche?}

Tive uma grande sorte de, como rapaz de 26 anos, conhecer escritores como Leib Rochman. Escritores de língua ídiche de Israel e de vários países vinham à casa dele. Ali eu conheci Sutzkever, Leivik, Opatoshu e outros escritores e poetas ídiches.

\section{Eles não o convenceram a escrever em ídiche?}

Eles se alegraram por eu me interessar, mas também entenderam que eu não possuía os instrumentos adequados. Eles, os escritores ídiches daquela época, tinham estudado em um

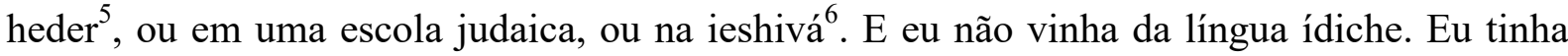
ouvido ídiche na infância; porém, ídiche não é minha língua materna. Mas eu aprendi a língua.

\section{É possível escrever numa língua que não seja língua-mãe?}

É possível, mas somente se não se tem outra língua da qual se seja desenraizado.

\section{Então, por que hebraico, e não ídiche?}

Se é que eu tenho uma língua materna, ela é a alemã. Mas hebraico foi a minha língua de cultura. Esforcei-me muito para aprender a língua, li muito a Bíblia, Mishná, Midrash, poesia, cabala e hassidismo. Mas, a bem da verdade, a língua em si não é o principal na minha obra. Para mim, ela é somente um meio para expressar sentimentos, pensamentos e fantasias.

\footnotetext{
${ }^{5}$ Escola judaica de ensino elementar onde crianças aprendem a ler hebraico, estudam a Bíblia e outros livros sagrados.

${ }^{6}$ Escola avançada de ensino judaico, com ênfase na interpretação de textos sagrados.
} 
Diversamente de muitos autores em hebraico, como Agnon, S. Izehar e outros, não uso formas complicadas da língua. Escrevo de modo nítido e simples.

\section{O senhor pode escrever hoje em ídiche? É possível?}

O estado sionista pecou ao não adotar o ídiche após a destruição. Temeu, em vão, que o ídiche retornaria como a língua popular em lugar do hebraico. Ídiche é uma conexão não somente com as vítimas, mas também com os mil anos durante os quais se falou ídiche, estudou-se ídiche e se gostava da língua. Naquela época, logo após a guerra, talvez fosse possível, mas hoje, lamentavelmente, é impossível.

\section{Mesmo que existam agora círculos de ídiche?}

Nas gerações anteriores, o ídiche era um órgão vivo do povo. E os grandes escritores Leyeles, Grade, Glatstein e outros - envidaram muitos estorços para pegar uma língua antiga e a transformar em uma língua moderna. Hoje, como é sabido, faltam-nos as condições necessárias.

\section{O que o senhor pensa dos idichistas contemporâneos?}

Entenda-se que todo empenho para que o ídiche não se perca é apreciável. Quem teria pensado, há 150 anos, que o hebraico se tornaria uma língua falada? Quando eu era criança, via meu avô rezar na língua sagrada. Eu sabia, então, que, mesmo eu sabendo ídiche, jamais conseguiria saber a língua sagrada. Quem pode ser um profeta? 